\title{
Low Doses of Memantine Disrupt Memory in Adult Rats
}

\author{
Catherine Creeley, ${ }^{1,2 *}$ David F. Wozniak, ${ }^{1 \star}$ Joanne Labruyere, ${ }^{1}$ George T. Taylor, ${ }^{2}$ and John W. Olney ${ }^{1 \star}$ \\ ${ }^{1}$ Department of Psychiatry, Washington University School of Medicine, St. Louis, Missouri 63110, and 2Department of Psychology, University of Missouri, \\ St. Louis, Missouri 63121
}

\begin{abstract}
Memantine, a drug recently approved for treatment of Alzheimer's disease, has been characterized as a unique NMDA antagonist that confers protection against excitotoxic neurodegeneration without the serious side effects that other NMDA antagonists are known to cause. In the present study, we determined what dose of memantine is required to protect the adult rat brain against an NMDA receptormediated excitotoxic process and then tested that dose and a range of lower doses to determine whether the drug in this dose range is associated with significant side effects. Consistent with previous research, we found that memantine confers a neuroprotective effect beginning at an intraperitoneal dose of $20 \mathrm{mg} / \mathrm{kg}$, a dose that we found, contrary to previous reports, produces locomotor disturbances severe enough to preclude testing for learning and memory effects. We then determined that, at intraperitoneal doses of $10 \mathrm{and} 5 \mathrm{mg} / \mathrm{kg}$, memantine disrupts both memory and locomotor behaviors. Rats treated with these doses performed at control-like levels in learning a hole-board task but were significantly impaired in demonstrating what they had learned when tested $24 \mathrm{~h}$ later. This impairment of memory retention was not state dependent in that it was demonstrable regardless of whether the rats were or were not exposed to memantine on the day of retention testing. We conclude that, in the adult rat, memantine behaves like other NMDA antagonists in that it is neuroprotective only at doses that produce intolerable side effects, including memory impairment.
\end{abstract}

Key words: memantine; neuroprotection; memory impairment; locomotor impairment; kainic acid; NMDA antagonists

\section{Introduction}

It is well established that glutamate excitotoxicity triggers neurodegeneration in acute brain injury conditions such as stroke, status epilepticus, and head trauma. Drugs that block NMDA glutamate receptors are known to be neuroprotective in animal models for studying these acute brain injury conditions (Olney, 1989; Choi, 1992a,b; Lipton and Rosenberg, 1994). Efforts to develop NMDA antagonist drugs for treatment of acute brain injury in humans have been uniformly unsuccessful because doses required for neuroprotection produce a variety of adverse side effects, ranging from acute psychotic manifestations in humans (Herrling, 1992; Krystal et al., 1994) to neuronal injury, locomotor impairment, and memory dysfunction in animals (Olney et al., 1989, 1991; Allen and Iversen, 1990; Wozniak et al., 1990, 1998; Fix et al., 1993; Hargreaves et al., 1993).

It has been proposed that a chronic low-grade excitotoxic mechanism may underlie the neurodegenerative process in $\mathrm{Alz}$ heimer's disease (AD), and this has kindled interest in the possibility that NMDA antagonists might arrest neurodegeneration and prevent cognitive deterioration in AD (Danysz and Parsons, 2003; Lipton, 2004a,b). Memantine has become recognized in recent years as an NMDA antagonist that is well tolerated by humans at doses that putatively are neuroprotective against excitotoxic neurodegeneration. It has been described as an agent that

Received Nov. 14, 2005; revised Feb. 28, 2006; accepted March 3, 2006

This work was supported in part by National Institutes of Health Grants AG 11355 and T32 MH14677.

${ }^{*}$ C.C., D.F.W., and J.W.O. contributed equally to this work.

Correspondence should be addressed to Dr. John W. Olney, Department of Psychiatry, Washington University

School of Medicine, Campus Box 8134, St. Louis, M0 63110. E-mail: olneyj@psychiatry.wustl.edu.

DOI:10.1523/JNEUROSCI.4883-05.2006

Copyright $\odot 2006$ Society for Neuroscience $\quad$ 0270-6474/06/263923-10\$15.00/0 has unique NMDA receptor binding kinetics that enable it to confer neuroprotective therapeutic benefits in the absence of neurotoxic or behavioral side effects (Chen et al., 1998; Danysz and Parsons, 2003). However, the experimental designs used in previous studies have not allowed for a full evaluation of the possible behavioral side effects of this drug at neuroprotective doses. Extensive research testing other NMDA antagonists in animal experiments has shown that these drugs cause neurobehavioral side effects, including both memory and locomotor disturbances, at doses substantially lower than are required for neuroprotective effects. Presumably, this signifies that only a slight degree of NMDA receptor blockade is required for neurobehavioral impairment, whereas a much greater degree is required to achieve neuroprotection. Regardless of where the truth lies in this theoretical debate, it is a practical fact that memantine was recently approved by the Food and Drug Administration (FDA) for treating patients with moderate to advanced Alzheimer's disease and is currently being widely marketed for this purpose. FDA approval was based on both preclinical studies describing neuroprotective effects in rats at doses reportedly free from side effects (Chen et al., 1998; Danysz and Parsons, 2003) and human clinical trials providing evidence for modest functional benefits at doses that were well tolerated by patients with Alzheimer's disease (Reisberg et al., 2003; Tariot et al., 2004).

The present study was undertaken to see whether we could confirm in adult rats that memantine is uniquely different from other NMDA antagonists. That is, does it have neuroprotective effects in the adult rat brain at doses that do not produce sensorimotor or memory disturbances? To address this question, we administered kainic acid (KA) to adult rats in a dose sufficient to trigger a seizure-related brain damage (SRBD) syndrome that 
NMDA antagonist drugs are known to protect against and determined what dose of memantine is required to provide significant protection. In other experiments, we administered memantine to adult rats, using doses at or below the dose required for neuroprotection, and evaluated the effects of these several doses on activity and sensorimotor performance and on tests of spatial memory acquisition and retention.

\section{Materials and Methods}

Animals. Adult Sprague Dawley female rats 6 to 8 months of age (270$363 \mathrm{~g}$ weight range) were used because female rats are more sensitive than males to adverse side effects of NMDA antagonists (Olney et al., 1989; Fix et al., 1995; Jevtovic-Tedorovic et al., 2001). All rats were housed in polypropylene cages with wood-chip bedding (three rats per cage) for the duration of the experiments and were maintained on a $12 \mathrm{~h} \mathrm{light/dark}$ schedule in a temperature- and humidity-controlled room. With the exception of those placed on food restriction, all animals were given access to food and water ad libitum. All experimental procedures were approved by the Animal Studies Committee of the Washington University School of Medicine.

Model for evaluating neuroprotective effects of memantine. To study the ability of memantine to protect against excitotoxic neurodegeneration, we used an excitotoxicity model in which rats are treated intraperitoneally with a dose of KA $(12 \mathrm{mg} / \mathrm{kg})$ that reliably triggers status epilepticus and an SRBD syndrome. When this dose of KA is administered to adult rats, it activates kainate receptors, which are highly concentrated in the CA3 region of the hippocampus. This excitatory stimulus is then propagated via the Shaffer collateral pathway to CA1 hippocampal pyramidal neurons and then via these neurons to extrahippocampal neurons that comprise a seizure-prone circuit within which the excitatory activity feeds on itself in a circular and reverberating pattern for several hours until many neurons within the circuit die from excitotoxic overstimulation. Although the syndrome is triggered by hyperactivation of kainate receptors, the seizure activity is propagated primarily though NMDA receptors. Therefore, the seizures can be arrested and the SRBD prevented by drugs that block NMDA receptors (Clifford et al., 1990). Thus, this is an excellent in vivo model for testing the efficacy of an NMDA antagonist drug in protecting against excitotoxic neurodegeneration. Various NMDA antagonists that have been tested in this model, including (+)-5-methyl-10,11dihydro-5H-dibenzo [a,d] cyclohepten-5,10-imine maleate (MK-801) and phencyclidine (PCP), act at the same site within the NMDA receptor ion channel as memantine. These agents typically arrest the seizure activity completely and prevent all manifestations of brain damage except for an acute edematous swelling of cell bodies and neuropil elements in the CA3 hippocampal region, in which KA directly exerts excitotoxic activity that is not blocked by the NMDA antagonist. Because CA1 hippocampal neurons are the first neurons in the path of propagation of this SRBD syndrome, a reliable and efficient method for evaluating the degree of neuroprotection conferred by an NMDA antagonist is to compare the SRBD manifestations in the CA3 and CA1 regions of the hippocampus. If the NMDA antagonist is effective, the neuropathological reaction in the CA3 region will not be diminished, but, in the CA1 region, it will be reduced to a degree commensurate with the efficacy of the NMDA antagonist in protecting against NMDA receptor-mediated excitotoxicity.

To determine whether memantine effectively protects against the KAinduced SRBD syndrome, rats were treated with KA alone $(12 \mathrm{mg} / \mathrm{kg} ; n=$ 14) or this dose of KA plus memantine $(10 \mathrm{mg} / \mathrm{kg}, n=6 ; 20 \mathrm{mg} / \mathrm{kg}, n=$ 10) and observed for seizure-related behaviors for $4 \mathrm{~h}$, anesthetized, and killed by perfusion fixation, and their brains were examined in the CA3 and CA1 regions for evidence of acute SRBD. Our research design called for testing memantine initially at a dose of $20 \mathrm{mg} / \mathrm{kg}$, and, if this dose of memantine was neuroprotective, additional doses were to be tested, each being one-half of the immediately preceding dose, until a dose was found that provided no neuroprotection. It was only necessary to test two doses because the first dose $(20 \mathrm{mg} / \mathrm{kg})$ provided significant neuroprotection and the next lower dose $(10 \mathrm{mg} / \mathrm{kg})$ did not. We chose $20 \mathrm{mg} / \mathrm{kg}$ as the initial dose because this is the dose that others have reported is effective in protecting the adult rat brain against excitotoxic neurodegeneration
(Wenk et al., 1994; Misztal et al., 1996; Danysz et al., 1997; Chen et al., 1998). Control animals for these experiments consisted of rats treated with saline $(n=3)$ or memantine at $10(n=6)$ and $20(n=6) \mathrm{mg} / \mathrm{kg}$ intraperitoneally. All agents were administered by intraperitoneal injection. Memantine hydrochloride (Sigma, St. Louis, MO) and kainic acid (Ocean Produce, Shelburne, Nova Scotia, Canada) were both dissolved in distilled water and adjusted with $\mathrm{NaOH}$ to a $\mathrm{pH}$ of 7.4.

Histopathology. Four hours after treatment, the animals were deeply anesthetized with chloral hydrate and perfused transcardially with a heparinized saline flush, followed by a fixative containing $2.5 \%$ paraformaldehyde and $1.5 \%$ glutaraldehyde in a $0.1 \mathrm{M}$ sodium phosphate buffer. The brains were then sliced into $1 \mathrm{~mm}$ transverse slabs, placed in osmium tetroxide overnight, dehydrated in alcohol, cleared in toluene, and embedded in Araldite. Using an ultramicrotome, the brains were sectioned coronally at $1 \mu \mathrm{m}$ and floated onto slides for staining with methylene blue/azure II. For evaluation of the histopathological reaction, sections were chosen from a rostrocaudal level at which the corpus callosum ceases decussating [bregma $-5.50 \mathrm{~mm}$ (Paxinos and Watson, 1998)]. At this level, the hippocampal formation is displayed to its fullest extent, including both dorsal and ventral aspects.

Quantitative evaluation of the SRBD reaction. Two trained histologists unaware of treatment condition examined the CA3 and CA1 regions of the hippocampus and assigned severity of damage scores on a scale of 0 (no pathology) to 4 (severe pathology). Criteria for assessing damage were the percentage of the pyramidal row of neurons displaying changes and the magnitude and type of changes. Typically dendritic processes and both neuronal and glial cell bodies show edematous swelling to a mild, moderate, or severe degree, and, when the reaction is most severe, it includes pyknotic changes in the nucleus of the affected neurons. All of these changes were factored into the brain damage score. The brain damage score of the two independent raters were averaged to obtain a single score for each of the brain regions (CA3 and CA1) of each animal, and the mean values for each region and each condition were determined. Calculation of Pearson's $r$ showed that the inter-rater reliability between the two sets of scores was significant $(r=0.70 ; p<0.0005$; Spearman's $\rho$ showed a similar degree of correlation).

Behavioral studies. Dose-response studies were conducted to determine the effects of memantine on locomotor activity, sensorimotor function, and spatial learning and memory as described below. Separate cohorts of naive rats were used for each study.

Locomotor activity test. To test the effects of memantine on locomotor activity, rats were randomly assigned to receive an injection of saline $(n=$ 22) or memantine at an intraperitoneal dose of $2.5,5,10$, or $20 \mathrm{mg} / \mathrm{kg}$ ( $n=6-8$ per dose). Immediately after injection, each animal was allowed to freely explore a standard $(44 \times 24 \times 21 \mathrm{~cm})$ empty polystyrene rat cage and was continuously monitored for $90 \mathrm{~min}$. The cage was surrounded by a $25 \times 45 \mathrm{~cm}$ frame containing a $4 \times 8$ matrix of photocell pairs located along the $x$ - and $y$-axes of the outside of each cage. Another frame, containing four photocell pairs along the length of the cage elevated $16.5 \mathrm{~cm}$ above the floor ( $z$ plane), recorded rearing events. The output of the photocells was fed to an on-line computer. Total ambulations, fine movements, and rearing events were quantified by system software (MotorMonitor; Hamilton-Kinder, Poway, CA). Total ambulations were defined as the number of times the animal changed its whole-body position, as measured by the breaking and clearing of two sequential pairs of photobeams horizontally along the $x$-and $y$-axes. Fine movements were defined as the number of times the animal moved without changing its whole-body position, measured by the breaking and clearing of a single pair of photobeams without ambulating and generally corresponds to small movements such as grooming or head shaking. Quantification of fine movements has also been used to estimate levels of stereotypical behaviors induced by NMDA antagonists, such as PCP, using the same behavioral testing system (Swanson and Schoepp, 2002). Rearing events were defined as the number of vertical beam breaks along the $z$ plane. The activity data were accumulated in 10 min bins. An a priori decision was made to restrict our assessment of activity measures to four posttreatment intervals $(10,30,60$, and $90 \mathrm{~min})$ to maintain adequate statistical power for evaluating drug effects at meaningful posttreatment times. 
Sensorimotor battery. To evaluate the effects of memantine on sensorimotor function, groups of rats were randomly assigned to receive an injection of saline or memantine at $2.5,5,10$, or $20 \mathrm{mg} / \mathrm{kg}$ intraperitoneally ( $n=12$ per group). Performance was assessed using four tests that were part of a larger battery of tests shown to be useful for detecting acute drug-induced disturbances in different aspects of sensorimotor function (initiation of movement, coordination, balance, and strength) after administration of another NMDA antagonist (MK-801) in rats (Wozniak et al., 1990). The maximal trial length was $60 \mathrm{~s}$. Testing began at $30 \mathrm{~min}$ after injection and was conducted in sequence as follows. (1) For "walking initiation," each rat was placed in the center of a square $(30 \times 30 \mathrm{~cm})$ outlined by white tape in the middle of a smooth black table top $(73 \times$ $103 \mathrm{~cm}$ ). Latency to move all four paws outside the boundary of the square was recorded. (2) For the "beam," each rat was placed on a narrow wooden beam $(70 \times 2.5 \times 49 \mathrm{~cm}$ high $)$ and allowed $60 \mathrm{~s}$ to traverse its length. Latency to fall was recorded. Performance on the beam was also scored using a 0 (immediate fall) to 5 (easily and completely traversed in both directions) scale. (3) For the "platform," each rat was placed onto a platform located atop a pole $(7.5 \times 15 \times 63 \mathrm{~cm}$ high $)$. Latency to fall from the platform was recorded. (4) For the " $90^{\circ}$ inclined screen," each rat was placed on a wire mesh grid $(54 \times 35 \mathrm{~cm} ; 1 \mathrm{~cm}$ squares $)$ inclined to $90^{\circ}$ relative to an elevated table top. They were placed on the middle of the screen, head down. Latency to turn $180^{\circ}$ and climb to the top of the screen was recorded.

Side effects index. To characterize dose-dependent side effects of memantine, we developed a global scale based on the number of activity and sensorimotor measures that showed significant differences (less than Bonferroni's corrected levels) between a memantine dose group and saline controls. For the sensorimotor measures (walking initiation, beam latency, beam performance, platform, and inclined screen), a memantine dose group received a score of 1 if it was significantly different from the saline control group. For example, with regard to beam performance scores, the 5,10 , and $20 \mathrm{mg} / \mathrm{kg}$ memantine groups were each significantly different from the saline control group, so each memantine group received a score of 1 for beam performance. For the activity measures (total ambulations, fine movements, and rearings), a memantine dose group received a score of 1 if that group was significantly different from saline controls on at least two of the four time periods of the test session. The scores were summed across the eight measures to yield a "side effects index" value.

Hole-board test of spatial learning and memory. The rotating holeboard task (Brosnan-Watters and Wozniak, 1997) was used to assess the effects of memantine on spatial learning and memory. The procedure used was directly adapted from a protocol developed for studying the effects of MK-801 on acquisition and retention of an appetitive spatial task in mice (Wozniak et al., 1996; Brosnan-Watters and Wozniak, 1997). Specifically, it is a reference-memory-based task shown to be sensitive for documenting acute impairments after a low dose of MK-801 (Brosnan-Watters et al., 1996) as well as long-term deficits resulting from neurotoxic doses of MK-801 (Wozniak et al., 1996). It involves training a rodent to poke its head into a hole and retrieve food reinforcement from a "baited" hole that contains a reinforcer on every trial. An animal is required to learn the spatial location of a baited hole in a single session, and a retention test is administered $24 \mathrm{~h}$ later.

The apparatus consisted of a square floor that contained a hole in each of the four corners and was enclosed by Plexiglas sides. Each hole contained a reinforcer consisting of a single piece of Post Fruity Pebbles cereal, which was made inaccessible by being placed under a screen at the bottom of a hole. The screen allowed the odor of the food (bait) to emanate from the hole but prevented access to it. When an individual hole was baited, a piece of cereal was placed on top of the screen, making the food accessible. The apparatus was placed on a turntable so that it could be rotated between trials during acquisition and retention sessions. Rats were handled, food restricted to $85-90 \%$ of their baseline ad libitum body weights, habituated to the apparatus and start tube, and trained to poke their heads into the exposed holes to retrieve the reinforcer. Fiftyone female naive rats were then randomly assigned to the following treatment groups: saline $(n=10)$ or memantine at $2.5 \mathrm{mg} / \mathrm{kg}(n=10), 5$ $\mathrm{mg} / \mathrm{kg}(n=12)$, or $10 \mathrm{mg} / \mathrm{kg}(n=19)$. Our experimental design origi- nally included memantine at $20 \mathrm{mg} / \mathrm{kg}$, but this dose so incapacitated the rats that none could perform the test. Unequal numbers were assigned to the memantine groups because we observed in pilot studies that some animals injected with memantine at doses lower than $20 \mathrm{mg} / \mathrm{kg}$ were likely to be dropped from testing for failure to perform (defined below). Therefore, the size of the memantine groups was increased to adjust for the potential loss of animals in those groups. For each experiment, the rats were weighed and injected with saline or memantine $30 \mathrm{~min}$ before the beginning of acquisition training. Each rat was randomly assigned to a baited hole location that remained the same for that rat throughout testing.

At the beginning of each acquisition trial, a rat was placed into an opaque plastic start tube, open at both ends, which was positioned in the center of the board. The tube was then removed, allowing the rat to begin exploration of the apparatus and poke its head into the holes until it retrieved the food reinforcer. Immediately after consuming the reinforcer, the rat was placed back into the start tube, the board was rotated $90^{\circ}$ on a pseudorandom basis, and the procedure was repeated. A trial ended when the food reward was consumed or 3 min elapsed. Rotation of the hole board before each trial prevented rats from using odor ("scent trails") or other proximal cues to locate the correct hole. The floor of the hole board was cleaned of urine and/or feces between trials. The repeated masking of old trails with new, along with the rotation of the board, was used to control for odor cues. For a given trial (except the first), the baited hole containing the reinforcer was different from the one used on the previous trial, although it was always located in the same relative spatial position whereby the baited hole was associated with the same distal cues. A trial was counted as correct only when the rat moved directly to, and ate from, the baited hole without poking its nose into any other hole on the board. An error was recorded if the rat poked its nose into an unbaited hole. A trial was recorded as failed if the animal did not find and consume the food reward in the 3 min time period. A rat that scored five consecutive failed trials in a row was dropped from additional testing for failure to perform. The rats were trained using a massed-trials protocol in which the above-described trials were repeated until they reached an a priori criterion of eight correct trials of nine consecutive trials. The total number of trials-to-criterion and errors committed in reaching criterion were recorded and served as dependent variables. A retention test was conducted $24 \mathrm{~h}$ after the acquisition session to evaluate the extent to which the mice retained what they had learned on the previous day. The protocol used during retention testing was the same as that used during acquisition except that no drug or saline was administered.

Hole-board test for state dependency. After the completion of the learning and memory experiments outlined above, a second hole-board experiment was conducted to test for possible state-dependent memory effects. A total of 22 rats were assigned to receive injections of saline $(n=$ 8 ) or memantine ( $10 \mathrm{mg} / \mathrm{kg} ; n=14)$ before both acquisition and retention test sessions. The rats were injected $30 \mathrm{~min}$ before acquisition and retention test sessions. The procedures for this experiment were identical to those outlined in the previous hole-board experiments, with the exception that the rats were treated before both acquisition and retention testing to evaluate possible state-dependent effects.

Statistical analyses. In general, the data were analyzed though the use of ANOVA models. Some models were one-way ANOVAs involving saline and various drug dosage groups. This type of ANOVA was used to evaluate the neuroprotective effects of memantine after KA administration. We felt this was a reasonable model to use because our severity of damage scale was continuous in nature and comprised equal intervals. Although the scale had a maximal assigned value, we felt that, given the design of our experiment, it was unlikely that this would lead to ceiling effects. Another ANOVA model often used on the behavioral data included one between-subjects variable (treatment groups) and usually one withinsubjects variable, such as blocks of trials or time periods. When ANOVAs with repeated measures were conducted, the Huynh-Feldt adjustment of degrees of freedom was used for all within-subjects effects containing more than two levels to generate appropriate $p$ values to help protect against violations of the sphericity/compound symmetry assumptions underlying this ANOVA model. Bonferroni's adjustment was used to maintain familywise $\alpha$ at 0.05 when multiple comparisons were conducted. 
Results

Neuroprotective effects of memantine

All animals treated with KA, regardless of whether they also received memantine, displayed behavioral automatisms of the type characteristically observed in KAtreated rats (Lothman and Collins, 1981). In the 30-45 min posttreatment period, they showed preconvulsive behaviors consisting primarily of staring spells and wetdog shakes. By 60-90 min, additional automatisms were manifested with increasing frequency, including facial twitching, eye blinking, chewing, and head nodding. By $120 \mathrm{~min}$, they were displaying conspicuous repetitive convulsive behaviors consisting of forelimb clonus, rearing on hindlimbs in a "praying" stance, loss of balance, falling, and copious salivation. Although there were individual differences in the rate at which these behaviors progressed, the rate of progression and severity of behavioral manifestations were similar for the KA-alone and KA plus memantine groups. Thus, in terms of seizurerelated behaviors, there was no apparent protective effect of memantine. This is in contrast to previously reported results with other NMDA antagonists, such as MK-801, which completely suppresses behavioral manifestations of KA-induced seizure activity (Clifford et al., 1990). For a detailed description of the behaviors manifested in animals treated with various doses of memantine alone, see below.

Histopathological evaluation of the brains $4 \mathrm{~h}$ after treatment revealed a severe degree of SRBD in both the CA3 and CA1 regions of the hippocampus in $100 \%$ of animals treated with KA alone (Fig. 1). The pathological changes consisted of conspicuous edematous swelling of dendritic endings and of specific neuronal and glial cell bodies, with clumping of nuclear chromatin in some neuronal profiles. The pattern and nature of these changes were identical to descriptions that have been reported previously in KA-treated rats (Olney, 1985; Clifford et al., 1990).

A significant one-way ANOVA showed that memantine treatment significantly affected the severity of damage in the CA1 region of the hippocampus $\left(F_{(2,27)}=16.84 ; p<0.0005\right)$. Subsequent pairwise comparisons revealed that, compared with the $\mathrm{KA}$-alone group, the $20 \mathrm{mg} / \mathrm{kg}$ group showed significantly less severity of damage. The $10 \mathrm{mg} / \mathrm{kg}$ dose, however, did not significantly reduce severity of damage $(p<0.0005)$ (Fig. 2). Memantine did not completely prevent CA1 hippocampal tissue damage in any animal compared with saline controls. These results are consistent with the observation that memantine also did not effectively prevent seizure activity in any animal. A nonsignificant ANOVA for the CA3 data showed that the memantine treatment did not affect severity of damage in this brain region at either dose (Fig. 2). Seizures and SRBD changes were not observed in any of the rats treated with saline or memantine alone.

\section{General behavioral responses to memantine}

During several of the behavioral tests, an experimenter who was unaware of the drug treatment status of individual animals recorded observations concerning the general posttreatment be-
KA 12
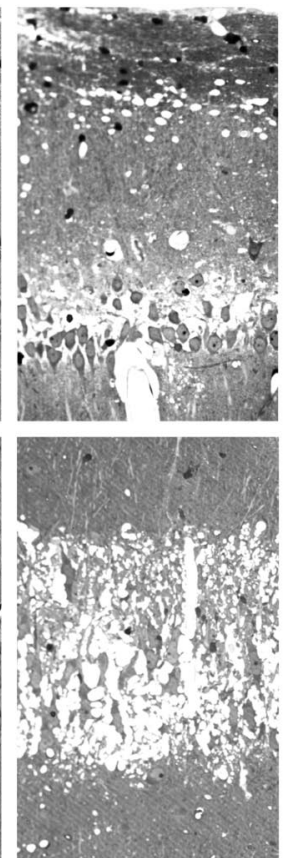
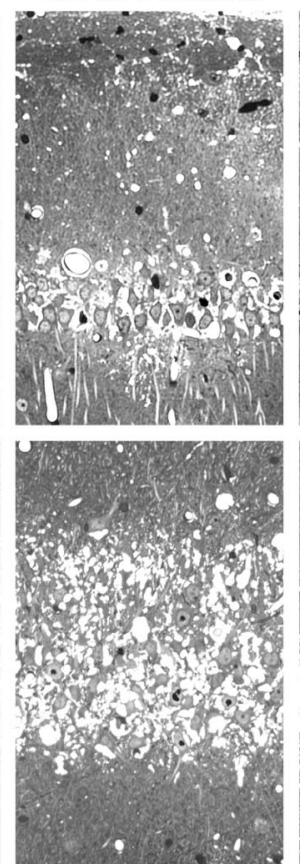

KA $12+\operatorname{Mem} 20$

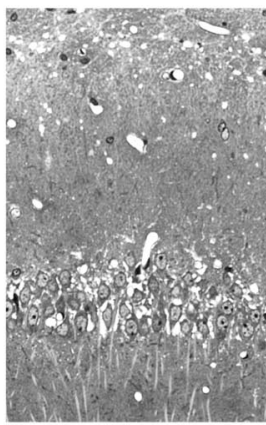

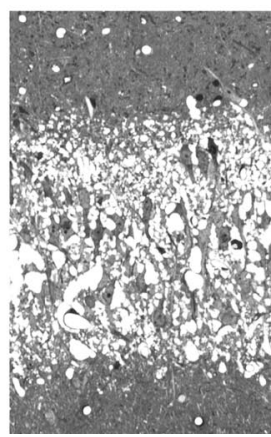

Figure 1. Appearance of the CA1 and CA3 hippocampal regions $4 \mathrm{~h}$ after treatment with $20 \mathrm{mg} / \mathrm{kg}$ memantine (Mem) or 12 $K A$-induced reaction is not appreciably modified in either the $C A 1$ or CA3 regions by $10 \mathrm{mg} / \mathrm{kg}$ memantine. Memantine at $20 \mathrm{mg} / \mathrm{kg}$ conferred no protection in the $\mathrm{CA} 3$ region but did reduce the severity of the reaction in the CA1 region.

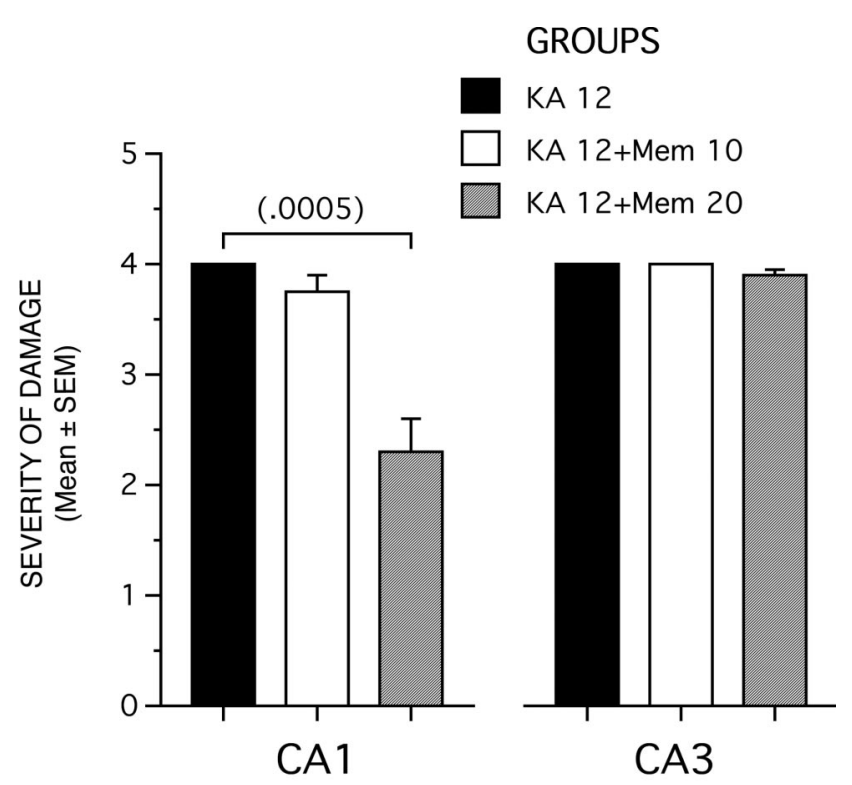

\section{HIPPOCAMPAL REGION}

Figure 2. Group mean severity of damage scores for the CA3 and CA1 subfields of the hippocampus showing that animals $(n=10)$ pretreated with 20 but not $10 \mathrm{mg} / \mathrm{kg}$ memantine (Mem) had significantly lower severity of damage scores in the CA1 region compared with those treated with KA alone $(n=14)$. Neither dose of memantine provided neuroprotection in the CA3 field.

havioral responses. After memantine injections, rats initially appeared lethargic and "dazed" in that they seemed less reactive to environmental stimuli compared with controls. Gradually, memantine-treated rats began displaying a combination of hy- 
Table 1. ANOVA summary from activity test

\begin{tabular}{lllrll}
\hline Variable & Effect & df & $F$ & $p$ & Simple main effects \\
\hline Total ambulations & Group & 4,45 & 1.93 & 0.12 & $10^{*}, 60^{*}, 90^{*}$ \\
& Time & 3,35 & 46.14 & 0.0005 & \\
Fine movements & Group $\times$ time & 12,135 & 18.80 & 0.0005 & \\
& Group & 4,45 & 8.31 & 0.0005 & $10^{*}, 30^{*}, 60^{*}, 90^{*}$ \\
& Time & 3,35 & 28.40 & 0.0005 & \\
Rearings & Group $\times$ time & 12,135 & 24.59 & 0.005 & \\
& Group & 4,45 & 6.65 & 0.0005 & $10^{*}, 30^{\dagger}, 60^{*}, 90^{*}$ \\
& Time & 3,35 & 36.06 & 0.0005 & \\
\hline
\end{tabular}

${ }^{*} p<0.0125$, Bonferroni's corrected level; ${ }^{\dagger} p<0.05$

a

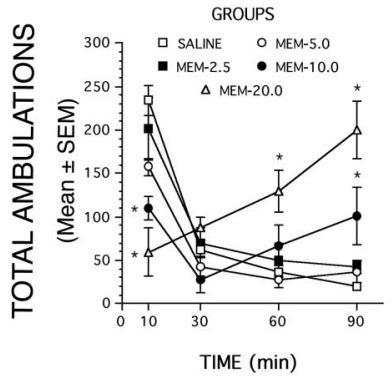

b

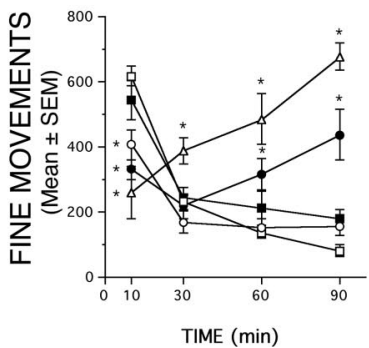

C

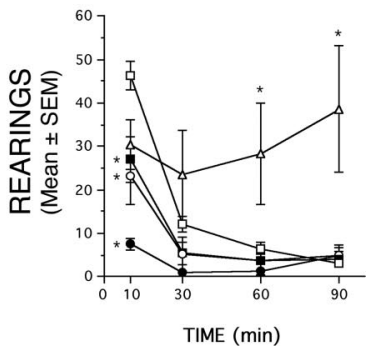

Figure 3. Group means for total ambulations, fine movements, and rearings across time after treatment with saline or 2.5, 5 , 10 , or $20 \mathrm{mg} / \mathrm{kg}$ doses of memantine. $\boldsymbol{a}$, For total ambulations (whole-body movements), animals treated with $10 \mathrm{or} 20 \mathrm{mg} / \mathrm{kg}$ showed significant $\left({ }^{*}\right)$ hypoactivity at the beginning of the test compared with saline controls. The numbers of total ambulations steadily decreased throughout the remainder of the test session in the saline and 2.5 and $5 \mathrm{mg} / \mathrm{kg}$ memantine Mem) groups. In contrast, the 10 and $20 \mathrm{mg} / \mathrm{kg}$ memantine groups showed progressive increases in activity, the latter group being significantly higher than saline controls at both 60 and $90 \mathrm{~min}$, and the former only at $90 \mathrm{~min}$. $\boldsymbol{b}$, Memantine produced similar changes in activity levels with regard to fine movements, except that differences were more extreme between the $10 \mathrm{and} 20 \mathrm{mg} / \mathrm{kg}$ memantine groups and saline controls at the later time points, and the $5 \mathrm{mg} / \mathrm{kg}$ memantine group had significantly fewer fine movements compared with saline controls at 10 min after treatment. $c$, The three lowest doses of memantine significantly decreased rearing at 10 min after treatment compared with the saline controls, although all four groups exhibited similar levels of decreased rearing throughout the rest of the test period. Numbers of rearings remained relatively high throughout the test session in the animals treated with $20 \mathrm{mg} / \mathrm{kg}$ memantine such that they showed significantly elevated levels at 60 and 90 min after treatment. ${ }^{*} p<$ 0.0125 , Bonferroni's corrected level.

peractive, stereotypical, and ataxic motor behaviors. These behaviors included head wagging, backward walking, and a waddling gait secondary to both trunkal and limb ataxia. These druginduced behaviors were most extreme and frequent in the 20 $\mathrm{mg} / \mathrm{kg}$ memantine group and appeared to decrease in a dosedependent manner (see side effects index below), although some ataxic tendency appeared to be present after 10 and $5 \mathrm{mg} / \mathrm{kg}$ doses.

\section{Locomotor activity}

In rats treated with $0,2.5,5,10$, and $20 \mathrm{mg} / \mathrm{kg}$ memantine, data for the activity parameters (total ambulations, fine movements, and rearing) were assessed for statistical significance at 10, 30, 60, and 90 min after treatment. A summary of the statistical results is listed in Table 1.

\section{Total ambulations}

In untreated control rats, total ambulations were markedly increased at $10 \mathrm{~min}$ after treatment (hyperactive response to an unfamiliar environment) but decreased dramatically by $30 \mathrm{~min}$ and continued to decrease for the remaining $60 \mathrm{~min}$ test period (Fig. $3 a$ ). There was a dose-related suppression of total ambulations in the memantine groups at $10 \mathrm{~min}$ after treatment. How- ever, in the 30-90 min interval, the 10 and $20 \mathrm{mg} / \mathrm{kg}$ memantine groups became progressively more hyperactive. This effect became most prominent at $90 \mathrm{~min}$ and was more pronounced with the $20 \mathrm{mg} / \mathrm{kg}$ dose (Fig. 3a). These trends were supported by an ANOVA and accompanying contrasts conducted on these data. Specifically, a significant main effect of time and a significant group $\times$ time interaction indicated that performance changed over time, with the extent of change dependent on the treatment group. Significant simple main effects were found at 10,60 , and 90 min, showing that the groups differed significantly in performance at these time points (Table 1). At $10 \mathrm{~min}$ after treatment, the saline controls were hyperactive relative to the 5,10 , and $20 \mathrm{mg} / \mathrm{kg}$ memantine groups $(p=0.016,0.001$, and 0.0005 , respectively). In contrast, the $20 \mathrm{mg} / \mathrm{kg}$ memantine rats were significantly more active than saline controls at $60 \mathrm{~min}$, whereas both the 10 and $20 \mathrm{mg} / \mathrm{kg}$ memantine groups were significantly more active than the controls at $90 \mathrm{~min}$ after treatment $(p=0.0005)$.

\section{Fine movements}

The effects of memantine on fine movements were very similar to the effects on total ambulations. In untreated control rats, fine movements were markedly increased at $10 \mathrm{~min}$ after treatment but decreased dramatically over the first $30 \mathrm{~min}$ and continued to decrease throughout the remaining test period. Memantine treatment caused deviations from this normal pattern of fine movements whereby there was a suppression of fine movements at 10 min after treatment in animals treated with the three highest doses of memantine $(5,10$, and $20 \mathrm{mg} / \mathrm{kg}$ ) compared with saline controls. However, in the 30-60 min interval, there was a crossover from hypoactive to hyperactive for animals treated with 10 or $20 \mathrm{mg} / \mathrm{kg}$ doses of memantine. This effect became progressively more extreme in the 60-90 min interval (Fig. 3b). An ANOVA of these data yielded significant main effects of group and time and a significant group $\times$ time interaction, showing that the performance of the treatment groups differed over time (Table 1). Significant simple main effects were found at each of the posttreatment time periods, indicating that group performances differed at those times. Pairwise comparisons conducted at $10 \mathrm{~min}$ after treatment confirmed that the saline controls exhibited significantly more fine movements than the 5,10 , and 20 $\mathrm{mg} / \mathrm{kg}$ memantine groups $(p=0.001,0.0005$, and 0.0005 , respectively). Additional pairwise comparisons conducted within each time period showed that the number of fine movements were significantly increased in the $20 \mathrm{mg} / \mathrm{kg}$ memantine group relative to saline controls for the 30,60 , and 90 min posttreatment times ( $p=0.001,0.005$, and 0.005 , respectively). Numbers of fine movements were also significantly increased in the $10 \mathrm{mg} / \mathrm{kg}$ memantine group relative to controls at 60 and $90 \mathrm{~min}$ after treatment ( $p=0.001$ and 0.0005 , respectively). 


\section{Rearing}

Memantine at $20 \mathrm{mg} / \mathrm{kg}$ induced relatively high levels of rearing at the beginning of the test session, which remained high throughout the 90 min posttreatment period. In contrast, the other memantinetreated rats showed an initial suppression of rearing at $10 \mathrm{~min}$. However, their levels and those of saline controls decreased and were essentially equivalent for the remainder of the test session (Fig. 3c). An ANOVA of the rearing data revealed significant main effects of group and time and a significant group $\times$ time interaction, indicating that group performances differed over time (Table 1). Significant simple main effects were found at each of the posttreatment time periods, showing differences among groups at each point. Pairwise comparisons conducted at 10 min confirmed that the saline controls exhibited significantly more rearings than the $2.5,5$, and $10 \mathrm{mg} / \mathrm{kg}$ memantine groups ( $p=0.003,0.001$, and 0.0005 , respectively). Additional pairwise comparisons conducted within each time period showed that the number of rearings was significantly increased in the $20 \mathrm{mg} / \mathrm{kg}$ memantine group relative to saline controls at 60 and $90 \mathrm{~min}$ after treatment ( $p=0.005$ and 0.005 , respectively).

\section{Sensorimotor battery}

Because gross differences in body weight can affect performance in certain sensorimotor tasks, we conducted a one-way ANOVA to test for possible differences in body weight among the treatment groups. The results showed no significant differences between groups for mean body weight. The results of the walking initiation test (Fig. 4a) suggest that memantine produced dose-dependent effects on performance. An ANOVA of these data revealed a significant effect of dose $\left(F_{(4,55)}=11.23 ; p=\right.$ $0.0005)$. A subsequent pairwise comparison showed that the rats in the $20 \mathrm{mg} / \mathrm{kg}$ memantine group took significantly longer to initiate movement out of the square $(p=0.0005)$ compared with the saline controls (Fig. 4a). The beam test included the most sensitive measures for detecting drug effects. For example, latency to fall from the beam (Fig. $4 b$ ) was also found to be dependent on the dose of memantine administered $\left(F_{(4,55)}=6.69 ; p=\right.$ $0.0005)$. The $2.5,5$, and $10 \mathrm{mg} / \mathrm{kg}$ doses of memantine decreased latency to fall from the beam to approximately equivalent levels. The 2.5 and $5.0 \mathrm{mg} / \mathrm{kg}$ memantine groups were each significantly different from saline controls $(p=0.010$ and 0.008 , respectively). Latencies were slightly longer and more variable for the 10 $\mathrm{mg} / \mathrm{kg}$ memantine group but were not significantly different. In contrast, there were profound differences in latencies to fall between the $20 \mathrm{mg} / \mathrm{kg}$ memantine group and saline controls ( $p=$ 0.0005). A somewhat similar dose dependency was found for performance scores during the beam test $\left(F_{(4,55)}=14.79 ; p=\right.$ $0.0005)$. The 5,10 , and $20 \mathrm{mg} / \mathrm{kg}$ memantine groups showed significantly lower scores when each was compared with saline controls $(p=0.0005)$. With the exception of the animals treated
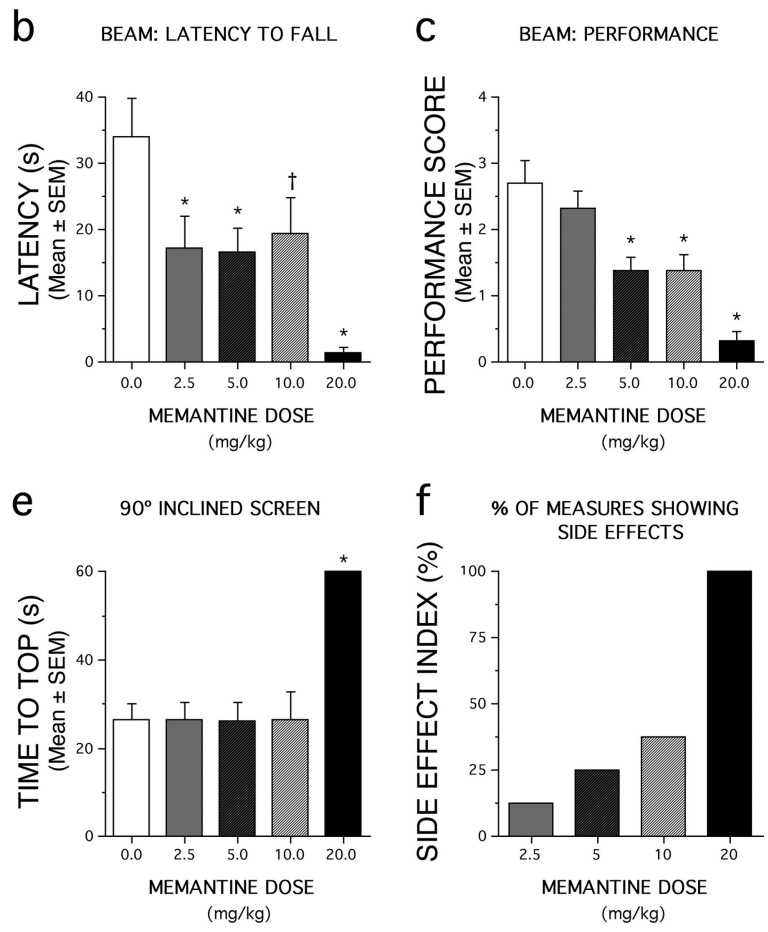

Figure 4. Effects of memantine on a battery of sensorimotor tests. $\boldsymbol{a}$, The results of the walking initiation test showing dose-dependent effects on performance. Animals in the $20 \mathrm{mg} / \mathrm{kg}$ memantine group took significantly $\left(^{*}\right)$ longer to initiate (he square compared with the saline controls. The 5 and $10 \mathrm{mg} / \mathrm{kg}$ memantine groups took substantially ( $p<$ Bonferroni's corrected level ( $p=0.0125)$ b Lared with the saline control group, although $p$ values were not less than the saline controls. The platform $(\boldsymbol{d})$ and $90^{\circ}$ inclined screen $(\boldsymbol{e})$ tests revealed a significant effect of memantine treatment attributable deficits in only one of eight measures. The 5 and $10 \mathrm{mg} / \mathrm{kg}$ doses of memantine produced an intermediate level of side effects. ${ }^{*} p<0.0125$, Bonferroni's corrected level; $0.0125<{ }^{\dagger} p<0.05$.

with $20 \mathrm{mg} / \mathrm{kg}$ memantine, the platform and $90^{\circ}$ inclined screen tests seemed to be the least sensitive in detecting differences between treatment groups (Fig. $4 d, e$ ). Although a significant effect of dose was found for both measures $\left(F_{(4,55)}=9.43, p=0.0005\right.$ and $F_{(4,55)}=12.74, p=0.0005$, respectively), subsequent pairwise comparisons showed that these effects were predominantly attributable to the poor performance of the $20 \mathrm{mg} / \mathrm{kg}$ memantine group ( $p=0.0005$ ) relative to the saline controls because the performance of all of the other memantine groups was not different from that of the saline controls. All of the groups also performed similarly during the inclined screen test, except for the $20 \mathrm{mg} / \mathrm{kg}$ memantine group, in which all of the rats were unable to remain on the screen long enough to climb to the top of the apparatus and thus were given maximal scores of $60 \mathrm{~s}$.

\section{Side effects index}

Compiling the results from the activity and sensorimotor tests to generate a side effects index resulted in a continuum of dosedependent side effects from memantine administration (Fig. $4 f$ ). At one end of the continuum, the $20 \mathrm{mg} / \mathrm{kg}$ dose produced side effects on every measure studied, whereas at the other end of the continuum, the $2.5 \mathrm{mg} / \mathrm{kg}$ dose produced side effects in only one of the eight measures. The 5 and $10 \mathrm{mg} / \mathrm{kg}$ doses of memantine 
Table 2. ANOVA summaries from dose-response and state-dependent hole-board experiments

\begin{tabular}{llcl}
\hline Effects & df & $\begin{array}{l}f \\
\text { (trials/errors) }\end{array}$ & $\begin{array}{c}p \\
\text { (trials/errors) }\end{array}$ \\
\hline $\begin{array}{l}\text { Dose-response } \\
\text { Dose }\end{array}$ & 3,50 & & $0.08 / 0.26$ \\
Test session & 1,50 & $2.39 / 1.36$ & 0.0005 \\
Dose $\times$ test session & 12,135 & $242.88 / 213.20$ & 0.0005 \\
$\quad$ Acquisition & 1,50 & $11.44 / 9.64$ & $0.62 / 0.61$ \\
Retention & 1,50 & $0.59 / 0.61$ & $0.0005^{* *}$ \\
$\quad$ Sal versus 2.5 Mem & 1,50 & $19.53 / 19.32$ & $0.05 / 0.12$ \\
$\quad$ Sal versus 5.0 Mem & 1,50 & $4.15 / 2.47$ & $0.001^{*} / 0.007^{*}$ \\
$\quad$ Sal versus 10.0 Mem & 1,50 & $13.53 / 7.98$ & $0.0005^{*}$ \\
State-dependent & & $56.31 / 56.46$ & $0.03 / 0.026$ \\
Drug (Sal vs Mem) & 1,14 & & $0.001 / 0.24$ \\
Drug $\times$ test session & 1,14 & $5.55 / 4.18$ & $0.80 / 0.46$ \\
Acquisition & 1,14 & $15.74 / 1.50$ & $0.0005^{* *}$ \\
Retention & 1,14 & $0.07 / 0.58$ & $26.59 / 30.80$ \\
\hline
\end{tabular}

${ }^{*} p<0.017,{ }^{* *} p<0.025$, Bonferroni's corrected levels. Mem, Memantine; Sal, saline. failure to perform (for description of the a priori criterion for exclusion attributable to nonperformance, see Materials and Methods). Twenty-six percent (5 of 19) of animals in the $10 \mathrm{mg} / \mathrm{kg}$ group and 25\% (3 of 12) of animals in the $5 \mathrm{mg} / \mathrm{kg}$ group were excluded from acquisition testing on day 1 for failure to perform after memantine treatment. No animals were excluded from the saline or $2.5 \mathrm{mg} / \mathrm{kg}$ memantine groups. The animals remaining in each group for statistical analyses were as follows: saline $(n=10)$ and memantine at 2.5 $\mathrm{mg} / \mathrm{kg}(n=10), 5 \mathrm{mg} / \mathrm{kg}(n=9)$, and 10 $\mathrm{mg} / \mathrm{kg}(n=14)$.

An overall ANOVA conducted on the acquisition and retention trials-tocriterion data revealed a significant main effect of test session (acquisition vs reten-

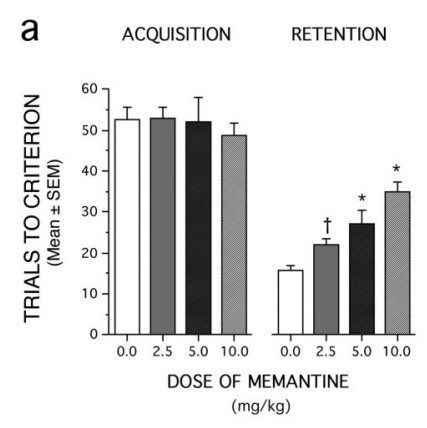

b ACQUISITION RETENTION

\section{C}

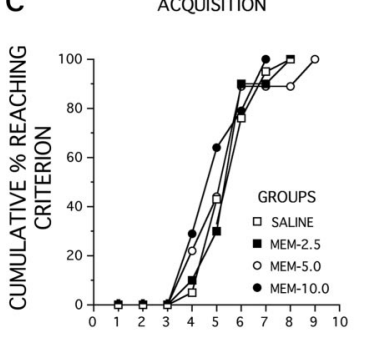

BLOCKS OF TRIALS

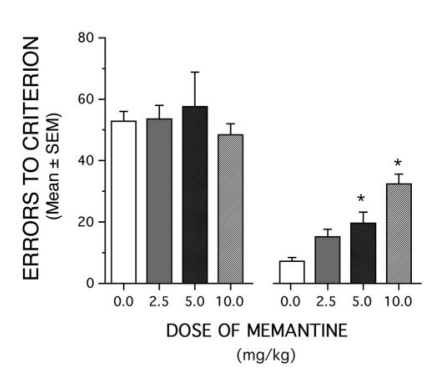

d RETENTION

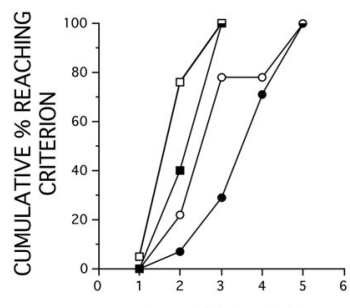

BLOCKS OF TRIALS
Figure 5. Effects of memantine on hole-board acquisition and retention performance. $\boldsymbol{a}$, Hole-board acquisition (spatial learning) performance was not impaired by any of the three doses $(2.5,5$, and $10 \mathrm{mg} / \mathrm{kg}$ ) of memantine (Mem) administered before testing. Testing $24 \mathrm{~h}$ later revealed a dose-dependent impairment in retention performance for animals treated with 5 or $10 \mathrm{mg} / \mathrm{kg}$ doses of memantine. $\boldsymbol{b}$, The same pattern of results was found for acquisition and retention with regard to errors committed in reaching criterion. $c$, The cumulative percentage of animals reaching criterion as a function of blocks of trials shows group performances over the posttreatment period, during which time very similar acquisition rates were observed for all of the groups. $\boldsymbol{d}$, In contrast, the animals that received the 5 or $10 \mathrm{mg} / \mathrm{kg}$ doses of memantine before acquisition testing exhibited slower rates to reach criterion during retention when tested 24 h later. ${ }^{*} p<0.017$, Bonferroni's corrected level; ${ }^{\dagger} p<0.05$.

produced intermediate levels of side effects that were fourfold to threefold less than that observed after the $20 \mathrm{mg} / \mathrm{kg}$ dose.

\section{Hole-board testing of spatial learning and memory}

The $20 \mathrm{mg} / \mathrm{kg}$ dose of memantine induced such gross behavioral disturbances that the rats could not be tested on the hole board after administration of this dose. Treatment with memantine at lower doses preceding acquisition trials on day 1 of hole-board testing induced lethargy, ataxia, and slowed movements in some animals such that some were excluded from additional testing for tion) and a significant dose $\times$ test session interaction (Table 2), showing that the animals generally performed better during retention compared with acquisition suggesting some learning had occurred, although the degree of learning depended on the type of treatment (memantine vs saline). An ANOVA conducted on the acquisition data (day 1) yielded a nonsignificant effect of dose, showing that spatial learning was not impaired by memantine at any dose $(2.5,5$, or $10 \mathrm{mg} / \mathrm{kg}$ ) (Fig. $5 a)$. In contrast, an ANOVA performed on the retention data from day 2 indicated that groups differed significantly in terms of performance, and subsequent pairwise comparisons indicated that this was mostly attributable to both the 5 and $10 \mathrm{mg} / \mathrm{kg}$ memantine groups being significantly impaired compared with saline controls $(p=0.001$ and 0.0005 , respectively). Impairment of memory retention was clearly a dose-dependent effect. That is, the degree of retention deficit demonstrable on day 2 depended on the dose of memantine administered before acquisition testing on day 1. A significant retention deficit effect ( $p<0.017$, Bonferroni's corrected) The same pattern of results was found for acquisition and retention when errors committed in reaching criterion served as the dependent variable (Table 2, Fig. 5). Group performances over time during acquisition and retention trials are shown in Figure $5, c$ and $d$. Note that the rates of reaching criterion are very similar for all of the groups during acquisition (Fig. $5 c$ ). In contrast, the rates of reaching criterion (Fig. $5 d$ ) are much slower in the 5 and $10 \mathrm{mg} / \mathrm{kg}$ memantine groups compared with the saline controls during retention trials, thus supporting the trials-to-criterion data cited above.

\section{Hole-board testing of state-dependent effects}

In the experiment just described, memantine was administered on day 1 , when acquisition performance was tested, but not on day 2 , when retention was evaluated. This raises the question of whether retention of memory for information learned under the influence of memantine is a state-dependent phenomenon. In other words, the information learned under the influence of memantine during acquisition trials on day 1 may be retrievable if the rats are tested on retention (day 2) when they are also under the influence of the drug. To evaluate this possibility, we conducted another experiment in which rats were treated with either saline or $10 \mathrm{mg} / \mathrm{kg}$ memantine on day 1 before acquisition trials and then received the same saline/drug treatment again on day 2 before retention testing. In this test, we found no evidence for a was seen for 5 and $10 \mathrm{mg} / \mathrm{kg}$ memantine compared with saline. 


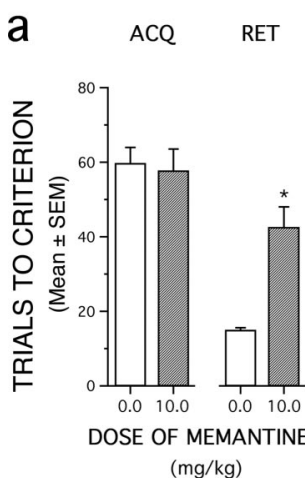

C

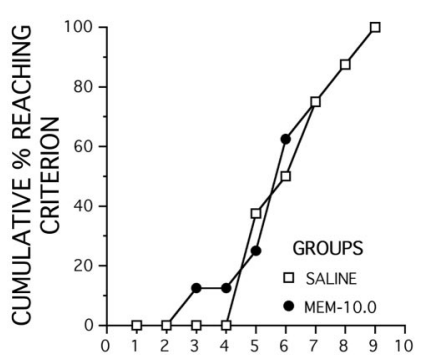

BLOCKS OF TRIALS

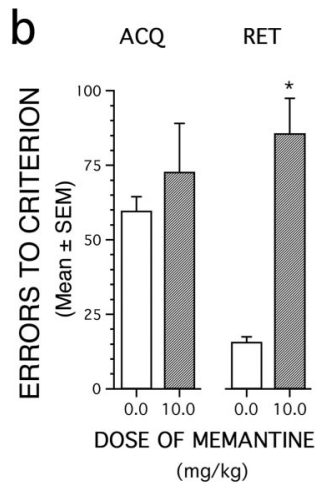

d

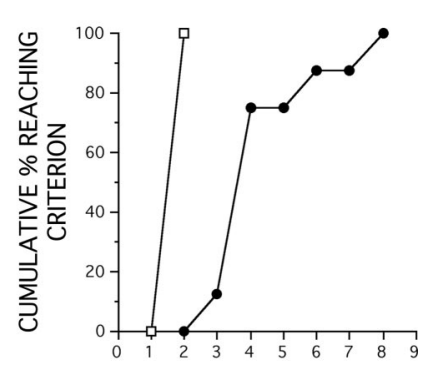

BLOCKS OF TRIALS
Figure 6. Testing the potential role of state dependency for retention of information acquired under the influence of memantine. Animals were treated either with saline or memantine $(10 \mathrm{mg} / \mathrm{kg}$; Mem) on day 1 before acquisition testing and also on day 2 before retention testing. On acquisition testing, the memantine-treated animals performed as well as saline controls with regard to both trials-to-criterion $(\boldsymbol{a})$ and errors $(\boldsymbol{b})$ but were significantly impaired on both measures during retention testing. Because the same retention deficit is demonstrable, regardless of whether the rats are or are not under the acute influence of memantine at the time of retention testing, the retention deficit cannot be explained in terms of a state dependency effect. ${ }^{*} p<0.0005$.

state-dependent learning effect but rather observed the same pattern of effects that were found in the first hole-board experiment (Fig. 6). Namely, on day 1, rats treated with $10 \mathrm{mg} / \mathrm{kg}$ memantine acquired the information as readily as the saline controls, as we had found previously, and this was confirmed by ANOVAs conducted on the trials-to-criterion (Fig. 6a) and error (Fig. 6b) data, which both yielded nonsignificant drug $(10 \mathrm{mg} / \mathrm{kg}$ memantine vs saline) effects (Table 2). However, on day 2, while under the influence of the same dose of memantine, ANOVAs conducted on the retention data showed that the drug-treated rats exhibited significantly impaired performance relative to the saline controls in terms of both trials-to-criterion and the number of errors committed during retention testing (Table 2). Group performance over time is shown in Figure 6, $c$ and $d$. Similar to the results from the previous experiment, during the acquisition testing, the memantine group reached criterion at approximately the same rate as the saline controls (Fig. $6 c$ ), although the rate of reaching criterion during retention testing was much slower for the memantine group.

\section{Discussion}

Our evaluation of memantine reveals that it has properties very similar to those of other NMDA antagonist drugs (i.e., MK-801, PCP, and ketamine) that share the same site of action within the NMDA receptor ion channel. In the adult rat, drugs acting at this site characteristically disrupt memory, produce sensorimotor disturbances, and induce distinctive behavioral stereotypies at doses lower than are required for neuroprotection against excitotoxic injury (Wozniak et al., 1990; Brosnan-Watters et al., 1996). In humans, NMDA antagonists typically trigger psychotic reactions at doses lower than are required to achieve a neuroprotective effect, and this is a major reason why drugs in this class have not been successfully developed as neuroprotectants. In human clinical trials, efforts to escalate the dose to a neuroprotective level have consistently resulted in intolerable side effects, resulting in the abandonment of the clinical research using this class of drug (Herrling, 1992; Grotta et al., 1995). Although memantine may be a substantially weaker NMDA antagonist compared with MK-801 or PCP, its adverse side effects/neuroprotection dose ratio is essentially identical to these agents in that it requires a moderate dose of memantine to trigger side effects and a substantially higher dose to provide therapeutic benefits. Our results show that, in adult rats, memantine, like other NMDA antagonists, disrupts memory and induces PCP-like stereotypies, sensorimotor disturbances, and alterations in activity at doses onequarter to one-half the dose required to provide minimal neuroprotection. Assuming that an excitotoxic mechanism underlies the neurodegenerative process in $\mathrm{AD}$, our finding that memantine is neuroprotective against kainic acid-induced excitotoxicity qualifies memantine as a rational therapy for $\mathrm{AD}$. However, our companion observation that it provides only weak neuroprotection at doses that produce severe sensorimotor and memory impairments suggests that its neuroprotective potential may be of limited practical value.

How can these findings be reconciled with claims that memantine provides protection against excitotoxic neurodegeneration in both adult rats and human $\mathrm{AD}$ patients at doses that are free from side effects? In an adult rat study (Chen et al., 1998) that is often cited by other authors (Parsons et al., 1999; Danysz and Parsons, 2003) as evidence for the neuroprotective effects of memantine in the absence of side effects, it is reported that memantine protects against hypoxic/ischemic brain damage but has no adverse effect on Morris water maze learning or on any other behavioral parameter. However, the statistical analysis of behavioral data presented by Chen et al. (1998) is limited to a comparison of memantine-treated and MK-801-treated rats. No statistical comparison was made between memantine-treated and saline control rats. They found that the learning and memory impairment induced by MK- 801 was significantly greater than that induced by memantine, but they failed to address whether memantine alone impairs learning and memory. Their conclusion that memantine lacks other behavioral side effects that NMDA antagonists are known to have was based on an anecdotal assessment without objective measures being performed. In contrast, our study is the first to systematically measure sensorimotor and learning and memory effects of memantine using a comprehensive battery of tests, including a task that evaluates spatial reference memory. Our findings are consistent with previous research with regard to the threshold for conferring neuroprotection in that we found that a $20 \mathrm{mg} / \mathrm{kg}$ dose was required for memantine to begin to produce an anti-excitotoxic neuroprotective effect. However, at $20 \mathrm{mg} / \mathrm{kg}$, there was only minimal neuroprotection, and this was accompanied by severe disruption of neurobehavioral functions. In fact, at this dose, all of the animals showed severe sensorimotor impairment, and, at one-half and onequarter of this dose, $\sim 25 \%$ of the animals could not complete the hole-board learning/memory task. Those that did complete the task showed significant impairment in memory retention.

The conclusion that memantine has a higher index of therapeutic safety than other NMDA antagonists is called into ques- 
tion by our findings and by the fact that previous studies have not adequately evaluated the neurobehavioral effects of memantine. Theoretically, because the neuroprotective benefits and adverse side effects of NMDA antagonist drugs are both dependent on the degree of blockade of the NMDA receptor, it is difficult to understand how any NMDA antagonist can block the NMDA receptor channel sufficiently to provide neuroprotection without such blockade being sufficient to produce adverse side effects. This is especially so because all NMDA antagonists that have been studied, including those that act at the same channel site as memantine, have been found to produce adverse side effects from lesser degrees of NMDA receptor blockade than are required to provide neuroprotective effects. Our findings support the conclusion that memantine is not uniquely different from other NMDA antagonists. It produces the same types of adverse side effects, including stereotypies and disruption of memory, as other NMDA antagonists, and it produces these effects at substantially lower doses than are required for neuroprotection.

The suggestion that memantine, in human $\mathrm{AD}$ patients, can enter the brain in concentrations sufficient to block NMDA receptors and, as a result, can selectively produce desired antiexcitotoxic beneficial effects that include improvement of cognitive functions while bypassing all side effects is inconsistent with the bulk of research information pertaining to NMDA antagonist drugs. Although potential species differences between rats and humans must be taken into consideration, the argument that memantine is uniquely more safe than other NMDA antagonists assumes that this is the case for both rats and humans. Indeed, it has been argued repeatedly (Chen et al., 1998; Parsons et al., 1999; Danysz and Parsons, 2003) that, in both rats and humans, memantine is uniquely different from other NMDA receptor antagonists in having distinctly different receptor kinetics that allow it to achieve a neuroprotective effect in either species at doses that are totally free from side effects. Our findings raise serious questions regarding the tenability of this argument. However, even if this argument proves untenable, this would not rule out a therapeutically beneficial effect of memantine in $\mathrm{AD}$ patients. Rather, it would suggest that, if the drug confers a benefit, it is likely not mediated though NMDA receptors. The fact that AD patients can be given memantine at a dose of $20 \mathrm{mg} / \mathrm{d}$ without incurring any NMDA antagonist type of side effect suggests that this dose produces concentrations of memantine in the human brain that are below the threshold for NMDA receptor antagonism. This interpretation is consistent with data from human clinical trials of memantine as a drug for relieving neuropathic pain. It has been shown repeatedly in animal studies that various NMDA antagonists (Davar et al., 1991; Backonja et al., 1994), including memantine (Neugebauer et al., 1993; Eisenberg et al., 1995), if administered at a dose that blocks NMDA receptors, can relieve neuropathic pain. In a clinical trial in which memantine was administered to neuropathic pain patients for 9 weeks at doses titrated to the individual patient's level of tolerance, the maximum tolerated dose was $55 \mathrm{mg} / \mathrm{d}$ (Sang et al., 2002). This was the dose at which subjectively determined disagreeable side effects began to occur, but, at this dose, there was no relief of neuropathic pain. This signifies that memantine in human patients produces adverse side effects at a dose lower than is required to provide a therapeutic benefit that clearly depends on blockade of NMDA receptors.

Thus, both animal and human data support the interpretation that memantine does not produce intolerable side effects in human $\mathrm{AD}$ patients because it is being used at doses that are below the threshold for interacting with NMDA receptors. This raises the possibility that the beneficial effects seen in $\mathrm{AD}$ patients may be attributable to the interaction of memantine with other transmitter systems. In fact, in their review of the preclinical studies for memantine as an anti-parkinsonian agent, Danysz et al. (1997) provide extensive evidence for interactions of memantine with dopaminergic, serotonergic, and cholinergic transmitter systems. It has also been found recently that memantine may interact more potently with cholinergic receptors than NMDA receptors (Aracava et al., 2005). This is of particular interest in the context of $\mathrm{AD}$ therapy in that the only approved $\mathrm{AD}$ therapies target the glutamatergic and cholinergic transmitter systems, and currently it is not uncommon for memantine (the only approved glutamatergic agent) to be administered to $\mathrm{AD}$ patients in combination with approved cholinergic agents (Tariot et al., 2004).

Clearly, if our interpretation is correct, it is untenable to maintain that memantine arrests neurodegeneration in $\mathrm{AD}$, or has any other beneficial effect in $\mathrm{AD}$, by blocking NMDA receptors. Moreover, there is no clinical evidence to support the notion that memantine arrests neurodegeneration in the human condition of $\mathrm{AD}$. If memantine is truly beneficial in $\mathrm{AD}$, and the benefit is not mediated by NMDA receptor blockade, it would be wise to shift emphasis away from the NMDA receptor and intensify research efforts to determine the real mechanistic basis for this beneficial effect with an aim toward developing new drugs that are safer and more effective.

\section{References}

Allen HL, Iversen LL (1990) Phencyclidine, dizocilipine, and cerebrocortical neurons. Science 247:221

Aracava Y, Pereira EFR, Maelicke A, Albuquerque EX (2005) Memantine blocks $\alpha 7^{\star}$ nicotinic acetylcholine receptors more potently than $\mathrm{N}$-methyl-D-aspartate receptors in rat hippocampal neurons. J Pharmacol Exp Ther 312: 3:1195-1205.

Backonja M, Arndt G, Gombar KA, Check B, Zimmermann M (1994) Response of chronic neuropathic pain syndromes to ketamine: a preliminary study. Pain 56:51-57.

Brosnan-Watters G, Wozniak DF (1997) A rotating holeboard procedure for testing drug effects on spatial learning and memory and mice. Brain Res Protoc 1:331-338.

Brosnan-Watters G, Wozniak DF, Nardi A, Olney JW (1996) Acute behavioral effects of MK-801 in the mouse. Pharmacol Biochem Behav 53:701-711.

Chen HS, Wang YF, Rayadu PV, Edgecomb P, Neill JC, Segal MM, Lipton SA, Jensen FE (1998) Neuroprotective concentrations of the $N$-methyl-Daspartate open-channel blocker memantine are effective without cytoplasmic vacuolation following post-ischemic administration and do not block maze learning or long-term potentiation. Neuroscience 86:1121-1132.

Choi DW (1992a) Bench to bedside: the glutamate connection. Science 258:241-243.

Choi DW (1992b) Excitotoxic cell death. J Neurobiol 23:1261-1276.

Clifford DB, Olney JW, Benz AM, Fuller TA, Zorumski CF (1990) Ketamine, phencyclidine, and MK-801 protect against kianic acid-induced seizure-related brain damage. Epilepsia 31:382-390.

Danysz W, Parsons CG (2003) The NMDA receptor antagonist memantine as a symptomological and neuroprotective treatment for Alzheimer's disease: preclinical evidence. Int J Geriatr Psychiatry 18 [Suppl 1]:S23-S32.

Danysz W, Parsons CG, Kornhuber J (1997) Aminoamantadines as NMDA receptor antagonists and antiparkinsonian agents: preclinical studies. Neurosci Biobehav Rev 21:455-468.

Davar G, Hama A, Deykin A, Vos B, Maciewicz R (1991) MK-801 blocks the development of thermal hyperalgesia in a rat model of experimental painful neuropathy. Brain Res 553:327-330.

Eisenberg E, La Cross S, Strassman AM (1995) The clinically tested $\mathrm{N}$-methyl-D-aspartate receptor antagonist memantine blocks and reverses thermal hyperalgesia in a rat model of painful mononeuropathy. Neurosci Lett 187:17-20.

Fix AS, Horn JW, Wightman KA, Johnson CA, Long CG, Storts RW, Farber N, Wozniak DF, Olney JW (1993) Neuronal vacuolization and necrosis 
induced by the noncompetitive $\mathrm{N}$-methyl-D-aspartate (NMDA) antagonist $\mathrm{MK}(+) 801$ (dizocilpine maleate): a light and electron microscopic evaluation of the rat retrosplenial cortex. Exp Neurol 123:204-215.

Fix AS, Wozniak DF, Truex LL, McEwen M, Miller JP, Olney JW (1995) Quantitative analysis of factors influencing neuronal necrosis induced by MK-801 in the rat posterior cingulate/retrosplenial cortex. Brain Res 696:194-204.

Grotta J, Clark W, Coull B, Pettigrew LC, Mackay B, Goldstein LB, Murphy D, LaRue L (1995) Safety and tolerability of the glutamate antagonist CGS 19755 (Selfotel) in patients with acute ischemic stroke. Results of a phase IIa randomized trial. Stroke 26:602-605.

Hargreaves RJ, Rigby M, Smith D, Hill RG, Iversen LL (1993) Competitive as well as uncompetitive $N$-methyl-D-aspartate antagonists affect cortical neuronal morphology and cerebral glucose metabolism. Neurochem Res 18:1263-1269.

Herrling P (1992) D-CPPene (SDZ EAA 494), a competitive NMDA antagonist: results from animal models and first results from humans. Neuropsychopharmacology 10:591S.

Jevtovic-Tedorovic V, Wozniak DW, Benshoff ND, Olney JW (2001) Comparative evaluation of the neurotoxic properties of ketamine and nitrous oxide. Brain Res 895:264-267.

Krystal JH, Karper LP, Seibyl JP, Freeman GK, Delaney R, Bremmer JD, Heninger GR, Bowers MB, Charney DS (1994) Subanesthetic effects of the noncompetitive NMDA antagonist, ketamine, in humans: psychotomimetic, perceptual, cognitive, and neuroendocrine responses. Arch Gen Psychiatry 51:199-214.

Lipton SA (2004a) Paradigm shift in NMDA receptor antagonist drug development: molecular mechanism of uncompetitive inhibition by memantine in treatment of Alzheimer's disease and other neurologic disorders. J Alzheimers Dis 6 [Suppl 6]:S61-S74.

Lipton SA (2004b) Failures and successes of NMDA antagonists: molecular basis for the use of open-channel blockers like memantine in treatment of acute and chonic neurological insults. NeuroRx 1:101-110.

Lipton SA, Rosenberg PA (1994) Excitatory amino acids as a final common pathway for neurologic disorders. N Engl J Med 330:613-622.

Lothman EW, Collins RC (1981) Kainic acid induced limbic seizures: metabolic, behavioral, electroencephalographic and neuropathological correlates. Brain Res 218:299-318.

Misztal M, Frankewicz T, Parsons CG, Danysz W (1996) Learning deficits induced by chronic intraventricular infusion of quinolinic acid-protection by MK-801 and memantine. Eur J Pharmacol 296:1-8.

Neugebauer V, Kornhuker J, Lucke T, Schaible HG (1993) The clinically available NMDA receptor antagonist memantine is antinociceptive on rat spinal neurons. NeuroReport 4:1259-1262.

Olney JW (1985) Excitatory transmitters and epilepsy-related brain damage. Int Rev Neurobiol 27:337-362.

Olney JW (1989) Excitotoxicity and $N$-methyl-D-aspartate receptors. Drug Dev Res 17:299-319.

Olney JW, Labruyere J, Price MT (1989) Pathological changes induced in cerebrocortical neurons by phencyclidine and related drugs. Science 244:1360-1362.

Olney JW, Labruyere J, Wang G, Wozniak DF, Price MT, Sesma MA (1991) NMDA antagonist neurotoxicity: mechanism and prevention. Science 254:1515-1518.

Parsons CG, Danysz W, Quack G (1999) Memantine is a clinically well tolerated $N$-methyl-D-aspartate (NMDA) receptor antagonist-a review of preclinical data. Neuropharmacology 38:735-767.

Paxinos G, Watson C (1998) The rat brain in stereotaxic coordinates, Ed 4. San Diego: Academic.

Reisberg B, Doody R, Stoffler A (2003) A randomized, placebo-controlled study of memantine, an uncompetitive NMDA antagonist, in patients with moderate to sever Alzheimer's disease. N Engl J Med 348:1333-1341.

Sang CN, Booher S, Gilron I, Parada S, Max MB (2002) Dextromethorphan and memantine in painful diabetic neuropathy and postherpetic neuralgia: efficacy and dose-response trials. Anesthesiology 96:1053-1061.

Swanson CJ, Schoepp DD (2002) The group II metabotropic glutamate receptor agonist (-)-2-oxa-4-aminobicyclo[3.1.0.]hexane-4,6-dicarboxylate (LY379268) and clozapine reverse phencyclidine-induced behaviors in monoamine-depleted rats. J Pharmacol Exp Ther 303:919-927.

Tariot PN, Farlow MR, Grossberg GT, Graham SM, McDonald S, Gergel I (2004) Memantine treatment in patients with moderate to severe Alzheimer disease already receiving donepezil: a randomized controlled trial. JAMA 291:317-324.

Wenk GL, Danysz W, Mobley SL (1994) Investigations of neurotoxicity and neuroprotection within the nucleus basalis of the rat. Brain Res 655:7-11.

Wozniak DF, Olney JW, Kettinger L, Price MT, Miller JP (1990) Behavioral effects of MK-801 in the rat. Psychopharmacology 101:47-56.

Wozniak DF, Brosnan-Watters G, Nardi A, McEwen M, Corso TD, Olney JW, Fix AS (1996) MK-801 neurotoxicity in male mice: histologic effects and chonic impairment in spatial learning. Brain Res 707:165-179.

Wozniak DF, Dikranian K, Ishimaru M, Nardi A, Corso TD, Olney JW, Fix AS (1998) Disseminated corticolimbic neuronal degeneration induced in rat brain by MK-801. Neurobiol Dis 5:305-322. 